
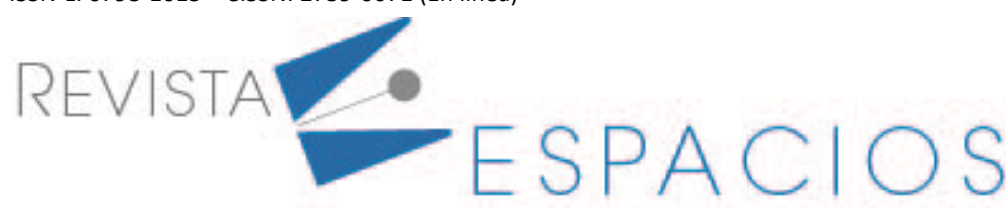

Educación • Education • Educação • Vol. 42 (15) 2021 • Art. 4

\title{
Um estudo sobre as abordagens da teoria dos campos conceituais nas pesquisas de ensino de probabilidade e estatística no Brasil
}

\section{A study on the approaches of the conceptual fields theory in research on the teaching of probability and statistics in Brazil}

\author{
DOMINGUES, Mateus Augusto Ferreira Garcia ${ }^{1}$ \\ SANTOS JUNIOR, Guataçara dos ${ }^{2}$ \\ PINHEIRO, Nilcéia Aparecida Maciel ${ }^{3}$ \\ MIQUELIN, Awdry Feisser ${ }^{4}$
}

\begin{abstract}
Resumo
O presente artigo visa investigar de que forma a Teoria dos Campos Conceituais está sendo abordada nas pesquisas de Ensino de Estatística e Probabilidade no Brasil a partir da revisão sistemática de literatura em teses e dissertações brasileiras entre 2010 e 2020. A busca foi realizada na Biblioteca Nacional Brasileira de Tese e Dissertação em 01/2021. Como questão de pesquisa, definiu-se o seguinte: de que forma a Teoria dos Campos Conceituais está sendo abordada nas pesquisas de Ensino de Estatística e Probabilidade? Foram aplicados os critérios de inclusão e exclusão com o propósito de selecionar, extrair e apresentar as informações dos trabalhos. Verificou-se que todos os trabalhos selecionados tiveram uma forma específica de utilizar a Teoria dos Campos Conceituais em suas análises, uns se envolveram mais com as invariantes operatórias, outros se preocuparam mais com as situações.
\end{abstract}

Palavras-chave: Campos conceituais; Ensino; Probabilidade; Estatística.

\begin{abstract}
This paper aims to investigate how the Conceptual Fields Theory is being addressed in research on Statistics and Probability Teaching in Brazil from a systematic literature review of Brazilian theses and dissertations between 2010 and 2020. The search was carried out in the Brazilian National Library of Theses and Dissertations in 01/2021. As a research question, the following was defined: how is the Theory of Conceptual Fields being addressed in research on Statistics and Probability Teaching? Inclusion and exclusion criteria were applied in order to select, extract and present information from the papers. It was verified that all the selected works had a specific way of using the Conceptual Fields Theory in their analyses, some were more involved with the operative invariants, others were more concerned with the situations.
\end{abstract}

Keywords: Conceptual Fields; Teaching; Probability; Statistics.

\footnotetext{
${ }^{1}$ Doutorando do Programa de Pós-Graduação em Ensino de Ciência e Tecnologia. Universidade Tecnológica Federal do Paraná. Email: mateusdomigues@alunos.utfpr.edu.br

${ }^{2}$ Doutor em Ciências Geodésicas. Professor do Programa de Pós-Graduação em Ensino de Ciência e Tecnologia da Universidade Tecnológica Federal do Paraná. Email: guata@utfpr.edu.br

${ }^{3}$ Doutora em Educação Cientifica e Tecnológica (UFSC). Professora da Universidade Tecnológica Federal do Paraná. Email: nilceiaamp@gmail.com ${ }^{4}$ Doutor em Educação Científica e Tecnológica (UFSC). Professor do Programa de Pós-Graduação em Ensino de Ciência e Tecnologia da Universidade Tecnológica Federal do Paraná. Email: awdry@utfpr.edu.br
} 


\section{Introdução}

O ensino de Probabilidade e Estatística está ganhando cada vez mais espaço na educação. Tais habilidades podem ser organizadas de forma que contribuam para o avanço da sociedade, principalmente em questões relacionadas a tomadas de decisões particulares de situações sociais e econômicas (MENEGHETTI; BATISTELA\& BICUDO, 2011) possibilitando que os sujeitos se tornem críticos e consigam ter uma voz ativa numa sociedade em que o excesso de informação está cada vez mais presente em vários contextos, jornais, revistas, mídias, redes sociais, dentre outros.

Das perspectivas epistemológica e ontológica, a Probabilidade e à Estatística são vistas como possibilidades de trabalhar com atividades escolares que tratam de incertezas e aleatoriedades, pondo um fim, desse modo, à aceitação unânime da lógica determinística e ao modo de conceber eventos como decorrentes de causas específicas e detectáveis com certeza científica (MENEGHETTI et al., 2011, pag. 812-813).

No entanto, ainda há muitas lacunas que, possivelmente, prejudicam os alunos com relação à capacidade crítica na percepção, assimilação, compreensão de índices sociais e econômicos; análise e interpretação de dados de gráficos (STURION et al., 2018). Essas barreiras epistemológicas podem acontecer porque, muitas vezes, os professores têm uma formação deficitária ou por falta de compreensão dos estudantes (BUENO et al., 2016).

Todavia, para que os estudantes consigam assimilar melhor os conceitos envolvidos nas áreas de conhecimento de estatística e probabilidade, é necessário elaborar propostas que possibilitem uma maior interação dos alunos com problemas do seu cotidiano, podendo, assim, possibilitar-lhes uma variedade de situações que contribua para uma aprendizagem significativa.

No que se refere à aprendizagem dos estudantes, tem-se a Teoria dos Campos Conceituais, que envolve um conjunto de situações ou problemas cujo tratamento carece de conceitos, procedimentos e representações. Essa teoria está estruturada da seguinte forma: conceito de esquema, situações, invariante operatório (teorema-emação ou conceito-em-ação). Diante disso, os indivíduos precisam dominar diversos conceitos em situações distintas, dado que diferentes conceitos estão presentes nas situações-problemas (MOREIRA, 1999, 2002).

Por meio dessas situações, é possível verificar a relevância dos conceitos Estatísticos e Probabilísticos presentes nas ações sociais, políticas e econômicas, assim como estar presente nos currículos das diversas áreas dos conhecimentos.

Com base nessas considerações, procurou-se realizar uma Revisão Sistemática da Literatura, tendo como motivação a utilização de situações-problemas que podem contribuir para que os alunos tenham uma aprendizagem significativa. Para tal, tem-se como base a Teoria dos Campos Conceituais, em que se relacionam os conceitos de situações, esquemas (invariantes operatórios) e representações (VERGNAUD, 1986, 1990, 1993, 2007).

Procurou-se, então, investigar de que forma a Teoria dos Campos Conceituais está sendo abordada nas pesquisas de Ensino de Estatística e Probabilidade. Para conduzir o trabalho da melhor maneira possível, foi elaborada a seguinte questão de pesquisa: de que forma a Teoria dos Campo Conceituais está sendo abordada nas pesquisas de Ensino de Estatísticas e Probabilidade?

Para responder a essa questão, este estudo está organizado em quatro seções. Na primeira, a introdução, justifica-se o porquê de realizar a pesquisa. Na segunda, apresenta-se a Teoria dos Campos Conceituais; na 
terceira, a metodologia. A quarta seção traz os resultados encontrados com base nas pesquisas analisadas e a quinta, as considerações finais.

\section{Teoria dos campos conceituais}

A Teoria dos Campos Conceituais foi desenvolvida com base no legado de Piaget (tendo como pedra angular o conceito de esquema) e de Vygotsky (sobre a importância de relacionar interação social, linguagem e simbolização).

É uma teoria psicológica, que tem como cerne o desenvolvimento cognitivo para dar sentido às diferenças que podem ser examinadas detalhadamente na conceitualização do real, que ocorre por meio de um conjunto informal e heterogêneo de problemas, situações, conceitos, relações, estruturas, conteúdos e operações de pensamentos (CEDRAN\&KIOURANIS, 2019; MOREIRA, 1999, 2002). Todas essas variáveis podem ser conectadas por intermédio do processo de aquisição do conhecimento, que também pode ser definido como um conjunto de situações que requer o domínio de diversos conceitos, procedimentos e representações de natureza distintas (VERGNAUD, 1990, 1993, 2007, 2013).

É uma teoria que proporciona uma estrutura coerente e alguns princípios que dão suporte para o estudo do desenvolvimento e da aprendizagem de competências complexas, especialmente as que se referem às ciências e às técnicas. "A sua principal finalidade é a de proporcionar um quadro que permita compreender as filiações e as rupturas entre conhecimentos, nas crianças e nos adolescentes, entendendo por 'conhecimentos', tanto o saber fazer, como os saberes expressados" (VERGNAUD, 1990, p. 1).

Vergnaud (1986) menciona que os conceitos não são construídos de forma isolada e que a compressão de um campo conceitual não acontece em meses, nem em anos, longe disso! Novas situações ou problemas e novas propriedades precisam ser estudadas durante um longo período para que os estudantes consigam dominá-las progressivamente (MOREIRA, 2002). Portanto, é praticamente improvável estudar os conceitos de forma separada, visto que os campos conceituais dão sentido aos problemas de aquisição e às observações realizadas por uma conexão com a conceitualização (VERGNAUD, 2018).

Partindo desse pressuposto, o conhecimento está estruturado em campos conceituais, tendo como foco o sujeito e ocorre pela experiência, maturidade e aprendizagem. Para isso, é necessário que praticamente todas as atenções estejam relacionadas às questões conceituais dos esquemas e às situações que os educandos desenvolvem, mais especificamente, seus esquemas na escola ou na vida real.

Esses esquemas não podem ser diminuídos a sua definição, uma vez que os conceitos adquirem sentido por meio de situações e problemas que surgem. (VERGNAUD, 1993). O conceito é uma tríade: $C=(S, I, R)$, em que $S$ é o conjunto de situações que fornece sentido ao conceito (referência); I é o conjunto de invariantes operatórios, ou o conjunto de invariante, que pode ser reconhecido e usado pelos sujeitos para examinar e dominar as situações do primeiro conjunto, pois é nos invariantes que estão os objetos (conceitos-em-ação e teorema-em-ação), o conjunto de operacionalidade dos esquemas, as propriedades, as relações (significado); R é o conjunto de representações (a linguagem natural, gráficos ou diagramas, sentenças formais, entre outras) que permite representar simbolicamente o conceito, suas propriedades, as situações e os procedimentos (significante). Essas representações podem ser utilizadas para indicar e descrever os invariantes, além de apresentar as situações e os procedimentos para enfrentá-los (VERGNAUD, 1986, 1990, 1993, 2007, 2011).

As formações dos conceitos podem ser um conjunto de invariantes possíveis de serem utilizadas nas ações, denominadas como operatórias, mas é preciso ter muito cuidado porque o real não pode ser conceitualizado por completo. "Não se discute a veracidade ou a falsidade de um enunciado totalmente implícito. Não se identificam os aspectos de real aos quais se deve prestar atenção sem ajuda das palavras, enunciados, símbolos 
e sinais" (VERGNAUD, 1993). Os significantes estão explícitos e é imprescindível à conceitualização, por esse motivo, não se descarta o papel da linguagem e do simbolismo (VERGNAUD, 1986, 1990, 1993).

A descrição de um campo conceitual requer ao mesmo tempo a análise das situações (ou dos problemas), a análise dos procedimentos de tratamento utilizados pelos alunos, os propósitos que têm e suas argumentações, as representações simbólicas que utilizam. $O$ uso de uma representação simbólica pode ser uma ajuda eficaz, mesmo crucial, podendo também dar lugar a graves erros de interpretações (VERGNAUD, 1986, 84).

A situação utilizada não é didática, é de tarefa. Todas as situações são complexas e podem ser analisadas como uma combinação de tarefas, portanto, é preciso conhecer suas naturezas e dificuldades. Todas as adversidades estão relacionadas na forma em que cada tarefa pode ser desempenhada, nas ações em que cada subtarefa afeta o desempenho do sujeito em sua totalidade. Por consequência, os processos cognitivos são encontrados nas respostas de cada indivíduo. Todavia, existem duas relações que dão sentido à situação: a variedade e a história. Praticamente todas as concepções possivelmente se apresentem por meio das primeiras situações que um sujeito pode dominar, suas experiências, procurando modificá-las (VERGNAUD, 1990, 1993).

Os esquemas partem de uma situação ou problema, e é por meio dele que se tem a tomada de decisão ou a conduta dos sujeitos. Portanto, há duas situações em que os esquemas aparecem. Na primeiro, o sujeito dispõe de competências necessárias para tratar de imediato uma situação. Nesse caso, a conduta do indivíduo é automatizada e o esquema é único. Há, também, a classe de situações para as quais os educandos não dispõem de competências necessárias. Em tal caso, a situação não é tratada de imediato. É necessário tempo para refletir, explorar e hesitar, pois, utiliza-se de vários esquemas que podem entrar em competição, o que pode ocasionar o sucesso ou fracasso (Figura 1).

Figura 1

Esquemas de como possivelmente funciona a tomada de decisão de um indivíduo

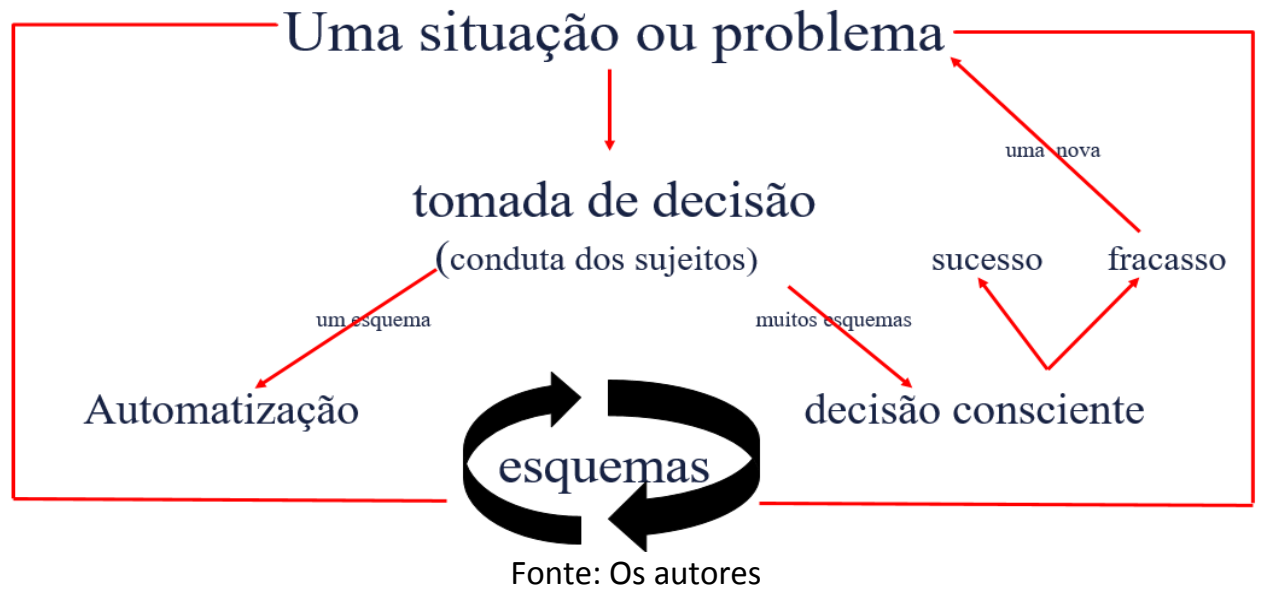

As situações não funcionam da mesma forma nos dois casos. No primeiro caso, os comportamentos são automatizados, organizados por apenas um esquema como já salientado. No segundo caso, utiliza-se de vários esquemas, que podem gerar conflito no inconsciente. Todavia, para obter sucesso e chegar à solução desejada, eles precisam ser acomodados, descomplicados e recombinados (MOREIRA, 1999).

O desenvolvimento cognitivo dos estudantes contém procedimentos que se automatizam de forma gradativa, logo, os seus julgamentos precisam estar baseados em crenças, princípios, regras, opiniões particulares de cada situação com as quais muitas vezes se deparam (VERGNAUD, 1990, 1993). “As situações dão sentido ao conceito, 
mas o sentido não se contém nas situações em si mesmas" (VERGNAUD, 1993, p. 18), por consequência, um conceito fica significativo mediante uma diversidade de situações. Pode-se dizer, então, que o sentido é o vínculo do indivíduo com as situações e com os significantes, não está nas situações, nas palavras nem nas representações simbólicas. Logo, é possível dizer o sentido está nos esquemas (MOREIRA, 1999). Contudo, um enunciado, uma palavra ou uma representação simbólica podem ter sentido, nenhum sentido ou vários sentidos para um determinado sujeito ou não (CEDRAN\& KIOURANIS, 2019). Consequentemente, sentido é o conjunto de esquemas que um sujeito invoca para agir diante de uma determinada situação, melhor dizendo, os comportamentos e sua organização, de forma mais específica, é uma conexão do sujeito com as situações e os significantes (VERGNAUD, 1989, 1990, 1993).

Nos esquemas estão os elementos cognitivos que fazem com que as ações dos sujeitos sejam operatórias, pois o conhecimento-em-ação de um sujeito é investigado nos esquemas. Para Vergnaud (1993), as situações são esquemas, então, a interação esquema-situações tem como componente fundamental os invariantes operatórios (conceitos-em-ação e teorema-em-ação). O conceito-em-ação é uma categoria de pensamento tida como pertinente e o teorema-em-ação é uma proposição considerada verdadeira sobre o real (VERGNAUD, 1986, 1990, 1993, 2007).

Quando o sujeito está acomodado, os esquemas podem ser imperfeitos, mesmo assim, ele pode se adaptar e ser capaz de ampliar aquele esquema com elementos cognitivos novos.Os invariantes operatórios são constituintes essenciais dos esquemas, mas não esgotam o seu conteúdo, nomeadamente devido ao seu papel essencial no funcionamento dos esquemas, dos objetivos, das regras e das inferências (VERGNAUD, 2012).

Figura 2

Uma estrutura do

Invariante Operatório

Aluno

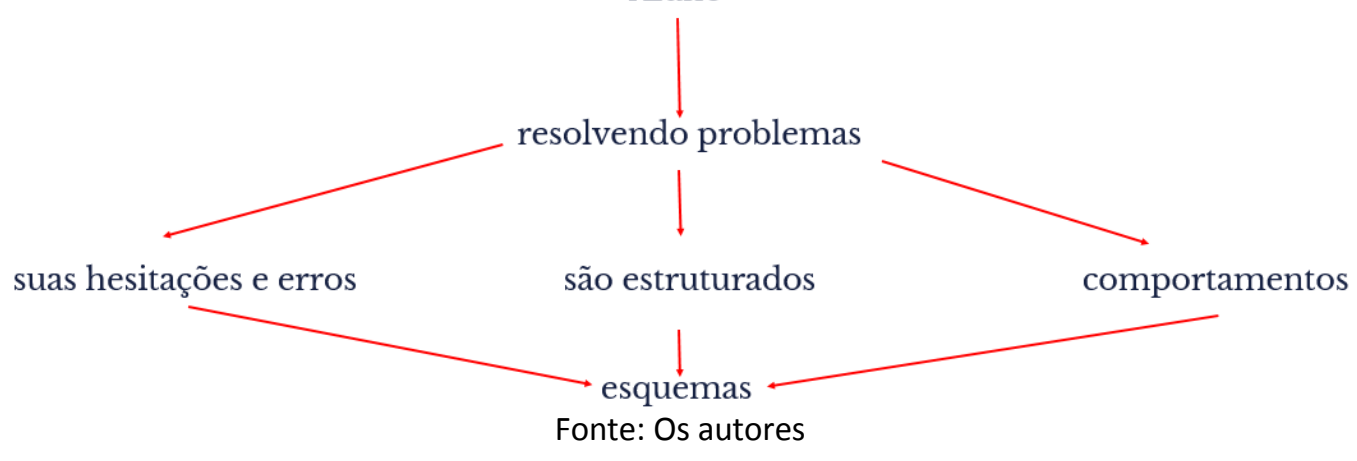

Como o teorema-em-ação e o conceito-em-ação são os conhecimentos contidos nos esquemas, quando um aluno se depara com uma situação-problema, e esse sujeito dispõe das competências necessárias, aplica-se o conceito de esquema. Os esquemas podem ser estruturados pelos comportamentos dos alunos durante a resolução de uma situação-problema, assim como a observação de suas hesitações e erros (Figura 2). Diversos esquemas podem ser invocados (reproduzido na imaginação), todos ao mesmo tempo, em uma nova situação ou considerada nova pelo estudante (VERGNAUD, 1993).

A observação dos alunos em situação de resolução de um problema, bem como a análise de suas hesitações e erros, mostra que os comportamentos em situação aberta são estruturados em esquema (os esquemas são apenas esboçados). Há muitos exemplos de esquemas que podem ser elaborados pelos sujeitos diante de uma situação nova ou não, no entanto, todos esses esquemas têm sua particularidade. Um sujeito (cada indivíduo estrutura seus esquemas de forma particular, a organização dos esquemas por parte de cada um é restrita e individual) organiza seus esquemas diante de uma situação ou problemas, mas, diante de uma situação, os 
esquemas podem ser amplos, generalizados ou descontextualizados, possibilitando que o aluno consiga superar aquela situação ou não (VERGNAUD, 1993).

Assim, a função do campo conceitual é auxiliar os alunos a fortalecerem seu repertório de esquemas e representações, já que eles podem desenvolver esquemas por meio de situações ou problemas que surgem. Os símbolos e a linguagem (significante) são cruciais durante o desenvolvimento da acomodação, e o professor é o mediador. Sua função é acompanhar os alunos durante todos esses processos, desde a escolha das situações e representações.

\section{Metodologia}

Nesta seção será apresentada a metodologia utilizada (que se trata de uma revisão sistemática da literatura): a questão da pesquisa, o objetivo e os critérios, estratégias de buscas, aplicações, inclusões e exclusões dos trabalhos relacionados à Teoria dos Campos Conceituais e o objeto de conhecimento de Estatística e Probabilidade.

A revisão sistemática da literatura oportuniza identificar, avaliar e interpretar estudos importantes dentro de uma área de conhecimento (KITCHENHAM, 2004, 2007). "Métodos sistemáticos são usados para evitar viés e possibilitar uma análise mais objetiva dos resultados, facilitando uma síntese conclusiva sobre determinada intervenção" (SAMPAIO\& MANCINI, 2007, p. 84). Por meio da revisão sistemática de literatura, é possível apresentar um parecer justo sobre um tema específico empregando uma metodologia confiável, mas, para isso, é preciso seguir estes procedimentos: planejar, conduzir e descrever os possíveis resultados encontrados. Como expressado por Sampaio e Mancini (2007, p. 85), "antes de se iniciar uma revisão sistemática, três etapas precisam ser consideradas, quais sejam: definir o objetivo da revisão, identificar a literatura e selecionar os estudos possíveis de serem incluídos".

Em uma revisão sistemática de literatura, primeiro se define a pergunta de partida; em seguida, é preciso identificar as bases de dados (localizar os estudos); estabelecer um critério para selecionar os estudos; um meio para conduzir e comparar esses trabalhos; aplicam-se critérios de inclusão ou exclusão; analisar e avaliar criteriosamente os trabalhos selecionados, elaborar um resumo sintetizando as informações e, por fim, apresentar uma conclusão com as evidências e os efeitos da intervenção (SAMPAIO\& MANCINI, 2007; ROTHER, 2007). Todas essas metodologias são utilizadas com o propósito de evitar que os resultados encontrados sejam tendenciosos (ROTHER, 2007).

Foi realizada uma consulta na Biblioteca Nacional Brasileira de Tese e Dissertação em janeiro de 2021, por meio de uma pesquisa qualitativa descritiva/interpretativa, procurando trabalhos publicados de 2010 até 2020, cujos títulos, resumos ou parte dos trabalhos apresentassem os seguintes critérios: Campos Conceituais; Estatística e Probabilidades. Os critérios adotados e a quantidade de trabalhos selecionados podem ser observados na Figura 3. 
Figura 3

Esquema de como foram

selecionados os trabalhos

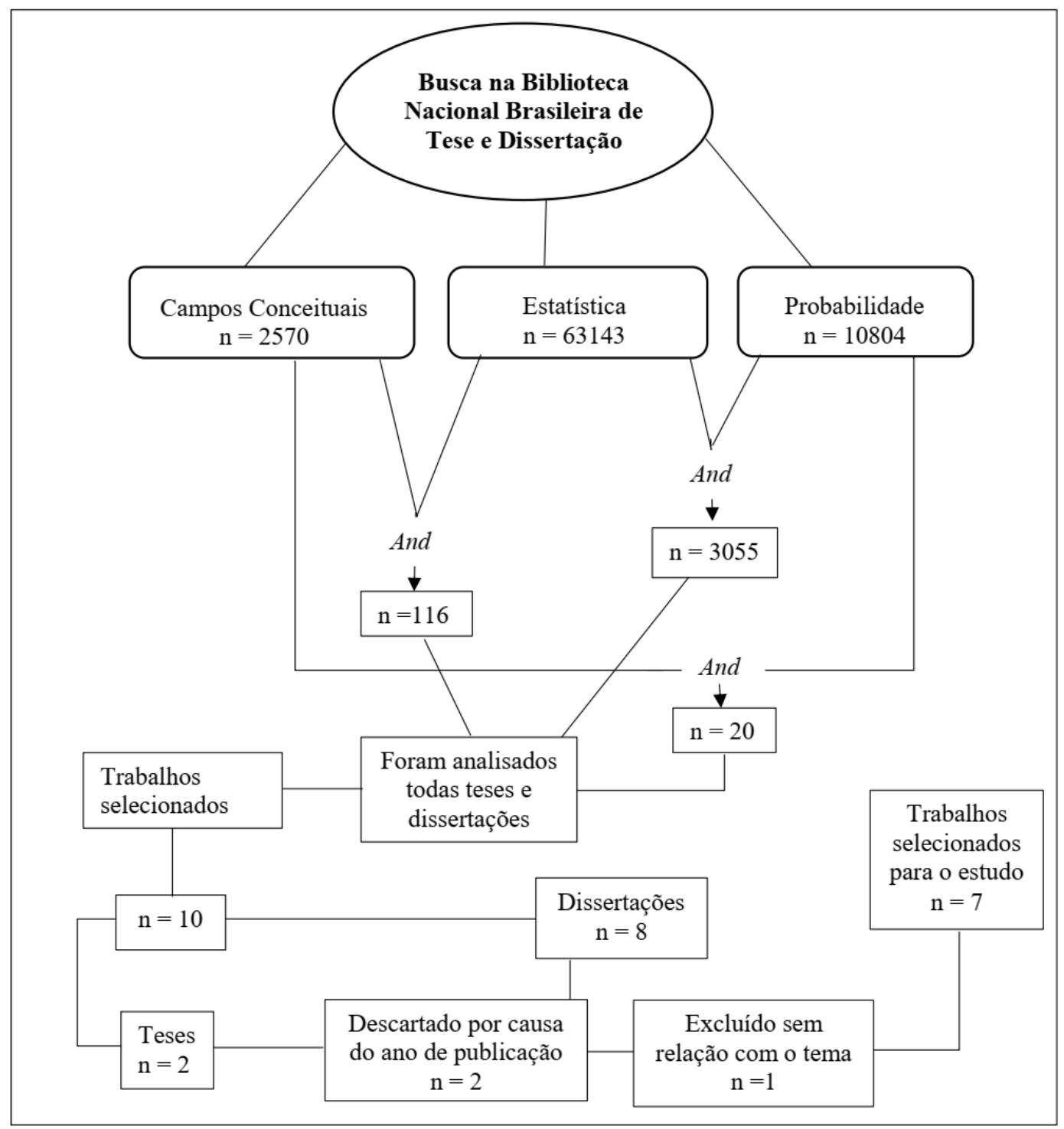

Fonte: Os Autores

Durante o processo de seleção, foram encontrados, ao todo, 10 trabalhos, sendo descartados dois por causa do ano de publicação. Os oito trabalhos selecionados foram examinados na íntegra. Após aplicados os critérios de inclusão e exclusão e feita uma leitura crítica, obteve-se como resultado sete trabalhos.

A pesquisa realizada por Castro (2016) foi descartada porque abordava conceitos de proporcionalidade, embora se soubesse da importância desse tema em relação ao objeto de conhecimento estatístico e probabilidade. Vergnaud $(1990,1993)$ reforça "[...] a importância epistemológica da proporção dupla (e múltipla) para a geometria, a física, as probabilidades e a estatística. [...] porque elas são conceitualmente mais difíceis, de outro [lado]porque elas acionam muitos elementos de uma só vez [...]".

$\mathrm{Na}$ próxima seção, serão apresentados os resultados encontrados, primeiro uma síntese dos trabalhos selecionados e, por conseguinte, as respostas da questão de pesquisa. 


\section{Resultados}

Esta seção traz uma seleção dos estudos que poderão oferecer respostas para a questão de pesquisa. No Quadro 1, estão organizados os trabalhos com suas respectivas identificações com o intuito de facilitar a sua referência no decorrer das discussões que serão apresentadas a seguir.

Quadro 1

Dissertações e Teses encontradas no portal da CAPES em 2021

\begin{tabular}{|c|c|c|c|c|c|}
\hline Código & Título & Autor (a) & Ano & Instituição & Tipo \\
\hline D1 & $\begin{array}{l}\text { Estatística para alunos do 60 ano do Ensino } \\
\text { Fundamental: um estudo dos conceitos } \\
\text { mobilizados na resolução de problemas }\end{array}$ & $\begin{array}{l}\text { Rebeca } \\
\text { Meirelles das } \\
\text { Chagas }\end{array}$ & 2010 & $\begin{array}{l}\text { Pontifícia } \\
\text { Universidade } \\
\text { Católica de São } \\
\text { Paulo }\end{array}$ & Dissertação \\
\hline D2 & $\begin{array}{c}\text { Estimativa de Medidas de Tendência } \\
\text { Central: uma } \\
\text { intervenção de ensino }\end{array}$ & $\begin{array}{l}\text { Ana Paula } \\
\text { Fernandes } \\
\text { Leite }\end{array}$ & 2010 & $\begin{array}{l}\text { Pontifícia } \\
\text { Universidade } \\
\text { Católica de São } \\
\text { Paulo }\end{array}$ & Dissertação \\
\hline D3 & $\begin{array}{c}\text { Média aritmética nos livros didáticos dos } \\
\text { anos finais } \\
\text { do ensino fundamental }\end{array}$ & $\begin{array}{l}\text { José Ivanildo } \\
\text { Felisberto de } \\
\text { Carvalho }\end{array}$ & 2011 & $\begin{array}{l}\text { Universidade } \\
\text { Federal de } \\
\text { Pernambuco }\end{array}$ & Dissertação \\
\hline D4 & $\begin{array}{l}\text { O acaso, o provável, o determinístico: } \\
\text { concepções econhecimentos probabilísticos } \\
\text { de professores do ensinofundamental }\end{array}$ & $\begin{array}{l}\text { Michaelle } \\
\text { Renata } \\
\text { Moraes de } \\
\text { Santana }\end{array}$ & 2011 & $\begin{array}{l}\text { Universidade } \\
\text { Federal de } \\
\text { Pernambuco }\end{array}$ & Dissertação \\
\hline D5 & $\begin{array}{l}\text { Letramento Probabilístico no Ensino Médio: } \\
\text { um estudo de } \\
\text { invariantes operatórios mobilizados por } \\
\text { alunos }\end{array}$ & $\begin{array}{l}\text { Cristiane } \\
\text { Candido Luz } \\
\text { Caberlim }\end{array}$ & 2015 & $\begin{array}{l}\text { Pontifícia } \\
\text { Universidade } \\
\text { Católica de São } \\
\text { Paulo }\end{array}$ & Dissertação \\
\hline D6 & $\begin{array}{l}\text { Mobilização Do Letramento Estatístico } \\
\text { Articulado AoContexto Socioambiental }\end{array}$ & $\begin{array}{l}\text { Douglas } \\
\text { Willian } \\
\text { Nogueira de } \\
\text { Souza } \\
\end{array}$ & 2018 & $\begin{array}{l}\text { Universidade } \\
\text { Federal Do } \\
\text { Amazonas }\end{array}$ & Dissertação \\
\hline $\mathrm{T} 1$ & $\begin{array}{l}\text { Formação Do Raciocínio Estatístico Na } \\
\text { Conceptualização Da Estimação Estatística: } \\
\text { Estudo Exploratório De Um Dispositivo } \\
\text { Pedagógico NoEnsino Superior }\end{array}$ & $\begin{array}{l}\text { Leonardo } \\
\text { Dalla Porta }\end{array}$ & 2019 & $\begin{array}{l}\text { Universidade } \\
\text { Franciscana }\end{array}$ & Tese \\
\hline
\end{tabular}

Fonte: Os autores.

Como já salientado, foram selecionadas seis dissertações (D1, D3, D4 e D6), que realizaram suas pesquisas no Ensino Fundamental. D1 aborda o conceito de covariação por meio da resolução de problemas, com questões que envolvem leitura, interpretação e construção de gráficos; D3 trata do conteúdo de média aritmética nos livros didáticos; D4 faz uma abordagem, na formação de professores, sobre o conhecimento probabilístico e D6 trata do letramento estatístico no contexto ambiental. Com relação ao Ensino Médio, têm-se a D2, cujo foco é o tópico de medidas de tendências centrais: média, moda e mediana, e a D5 que trata do letramento probabilístico. Com abordagem no Ensino Superior, tem-se o trabalho T1, que versa sobre o raciocínio estatístico. Todos os trabalhos trazem uma abordagem dos Campos Conceituais para o ensino de probabilidade ou estatística.

A pesquisa D1, realizada por Chagas (2010), teve como objetivo identificar a percepção e o nível de raciocínio da variabilidade com alunos do Ensino Fundamental de uma escola pública. Foram discutidas questões que 
envolvem leitura, interpretação e construção de gráficos. A autora procurou identificar quais invariantes operatórios estão relacionados ao tema de variabilidade. Para isso, foi considerada a Teoria dos Campos Conceituais procurando identificar os invariantes operatórios (teorema-em-ação e conceito-em-ação) em situações de resolução de problemas.Os resultados mostraram que os alunos têm algumas dificuldades de leitura, interpretação e construção de gráficos em situações particulares, mais especificamente, gráficos de escalas não unitárias com frequência nula relativa ao conceito-em-ação: "a frequência é contagem, logo não pode ser nula" e "frequência representa contagem, logo deve ser representada em escala unitária". Os alunos também apresentaram dificuldades com escalas não unitárias, conceito ausente de raciocínio proporcional.

O estudo D3, de Carvalho (2011), analisou como a abordagem do conceito de média aritmética está presente nos livros didáticos aprovados pelo PNLD 2011 do Ensino Fundamental, tendo como base a Teoria dos Campos Conceituais. Por meio de um parecer crítico das atividades, organizaram um banco de dados classificando-as sob uma ótica dos invariantes prescritos, os significados, as representações exploradas, o tipo de contexto e variáveis envolvidas. $O$ autor percebeu que os dados presentes nos livros demonstravam limitações nas explorações pertencentes ao conjunto de invariantes, significados e representações. Nos livros analisados, o campo conceitual da média é tratado de forma fragmentada, além de não permitir uma compreensão de média como uma média estatística, porque há poucas atividades na composição da abordagem das coleções que assegure a compreensão por parte do estudante da função estatística da média aritmética. Carvalho (2011) não teve a intenção de verificar apenas o fracasso e as lacunas conceituais da média nos livros didáticos, procurou evidenciar que, a partir de sua análise, pode-se progredir para melhores abordagens didáticas com relação ao conceito de média aritmética.

O trabalho D4, executado por Santana (2011), procurou identificar como professores compreendem a importância do ensino de probabilidade; além de verificar quais motivos os fazem explorar ou não esse conceito em suas aulas. Analisou, ainda, os conhecimentos vivenciados pelos professores em diferentes níveis de ensino e verificou que noções eles consideram necessárias para a construção desse conceito. A autora acredita que compreender as relações dos acontecimentos cotidianos é de natureza aleatória e que os conceitos que envolvem probabilidade estão envoltos desses acontecimentos, além de abranger uma diversidade de outros conteúdos, como fração, razão, porcentagem, chance, acaso, dentre outros. Santana (2011) evidenciou que há uma diversidade de sentidos que foram atribuídos pelos professores, os quais revelaram suas dúvidas e incompreensões sobre as noções básicas relacionadas ao conhecimento probabilístico, que é muito pouco explorado no Ensino Fundamental, e justifica que os livros didáticos não oferecem subsídio para trabalhar com esse conteúdo. Diante dessa fragilidade apresentada pelos professores, surgem dificuldades de explorar a probabilidade em sala de aula. A autora expressa que, sem compreensão conceitual, dificilmente os professores conseguiram construir significativamente os conceitos necessários para a aprendizagem das noções de probabilidade. E conclui que há uma dificuldade na compreensão das noções probabilísticas, além de reforçar a necessidade de pesquisa acadêmica referente ao ensino de probabilidade e suas noções básicas. Sendo assim, é preciso oportunizar ao professor, durante sua formação inicial, discussões referentes ao ensino de probabilidade para que ele possa ter autonomia para trabalhar esse tema.

A dissertação D6, elaborada por Souza (2018), teve como finalidade analisar se o letramento estatístico ocorre em alunos do 5o ano do Ensino Fundamental por intermédio da articulação com o contexto ambiental. Ele associou o letramento estatístico com o contexto socioambiental em situações propostas: "Coleta Seletiva na escola", "Horta vertical com garrafas PET" e "Piquenique Sustentável" com os alunos, em que a Teoria dos Campos Conceituais possibilitou que houvesse uma estrutura teórica do desenvolvimento cognitivo desses sujeitos em situações de aprendizagem. O autor elaborou seis teoremas-sem-ação associados com os três níveis de letramento estatístico (cultural, funcional e científico) articulando-os com o contexto socioambiental. Para ele, o letramento estatístico não se resume a uma definição, é um conjunto de situações dos invariantes e das 
linguagens pertinentes aos conceitos. Segundo Souza (2018), as atitudes humanas estão interligadas e podem ser alcançadas por meio de intervenções/ações que têm o potencial de provocar impactos positivos/negativos à natureza. Por esse motivo, trabalhou com o contexto socioambiental. Ele percebeu que os níveis de letramento estatístico, apoiado na Teoria dos Campos Conceituais, possibilitam indicar que os educandos tiveram algumas dificuldades de aprendizagem em matemática, pois os alunos não apresentavam resultados satisfatórios na disciplina. Apesar disso, foi possível inferir e associar o letramento estatístico com o contexto ambiental, e as sugestões socioambientais mostraram-se relevantes tanto como propostas de sensibilização, quanto de integração curricular.

A pesquisa D2, produzida por Leite (2010), investigou as contribuições de uma intervenção de ensino, pautada na significação e estimativa das medidas de tendência central, tendo suporte em leitura e interpretação de tabelas e gráficos. Seu estudo foi estruturado com base na Teoria dos Campos Conceituais com intervenções voltadas para a conceitualização e a estimativa dessas medidas. Os alunos conseguiram, de forma gradativa, desenvolver as competências necessárias. Essas habilidades possivelmente tiveram como causa as diferentes situações apresentadas, que estavam apoiadas nas experiências dos estudantes, as quais era possível relacionar com seu contexto dentro ou fora do ambiente escolar. Diante disso, pôde-se inferir que houve ganho cognitivo dos alunos no processo de aprendizagem de estatística, em específico, de medidas de tendência central (média, moda e mediana). No que se refere à conceitualização construção de conceito, houve um crescimento significativo das três medidas, média, moda e mediana, por parte dos alunos. Quanto à representação simbólica, ela favoreceu a leitura e a compreensão da estimativa de medidas abordadas. Percebeu-se, também, que os alunos têm maior facilidade/familiaridade quando as representações tratam de assuntos de seu interesse ou fazem parte de seu contexto socioeconômico e cultural. Então, como sugestão, os professores podem elaborar situações que satisfaçam esse interesse fortalecendo o hábito de trabalhar com a estimativa, contribuindo para o amadurecimento da conceitualização.

A pesquisa D5, elaborada por Caberlim (2015), teve como foco diagnosticar invariantes operatórios mobilizados pelos alunos em situação de resolução de problemas. Para isso, procuraram elementos que permitissem uma proposta de modelo de construção de conceitos (modelo de evolução da aprendizagem), especificamente o letramento probabilístico dos estudantes. A autora comparou os invariantes identificados com os elementos do letramento probabilístico procurando associá-los com a definição clássica e o enfoque frequentista da probabilidade. Caberlim (2015) relata que, durante as atividades propostas, por meio da análise dos protocolos, conseguiu identificar que os alunos mobilizaram os invariantes operatórios que possibilitam estimar a probabilidade, confirmando a hipótese de desenvolvimento do letramento probabilístico. No entanto, nenhum aluno atingiu o letramento probabilístico pleno atribuído à resolução de problemas no domínio abstrato, conforme proposto no esquema para um processo de abstração a ser percorrido no decorrer da aprendizagem. Mesmo assim, houve uma evolução que tornou possível a apropriação do conhecimento pelos alunos.

A tese T1, desenvolvida por Porta (2019), procurou entender melhor o processo de formação do raciocínio estatístico na aprendizagem da estimação estatística no Ensino Superior, por meio da conceitualização. Foram pesquisados diversos trabalhos que tratam da competência estatística: letramento, pensamento e raciocínio estatísticos. Também utilizou como referencial a Teoria dos Campos Conceituais. Como resultados, os estudantes com mais afinidade com o conceito de estatística tiveram melhor desempenho. Esses alunos utilizaram os conceitos aprendidos convictos do que estavam fazendo. Portanto, as orientações (questões como as situações-problemas) relacionadas com a estimação estatística e a relação do estudante com a estatística podem influenciar na formação do raciocínio estatístico, principalmente em razão de problemas matemáticos.

Dando voz à pergunta de pesquisa, procurou-se verificar a como os campos conceituais foram abordados na pesquisa de Ensino de Probabilidade e Estatística. 
No que se refere ao ensino de Probabilidade, foram encontrados dois trabalhos: D4 e D5. O primeiro (D4) traz uma abordagem na formação de professores sobre o conhecimento probabilístico e o segundo (D5) trata do letramento probabilístico. Ambos os trabalhos trataram da construção de conceitos, mas a D4 foi o trabalho que melhor especificou como as relações de conceitos, as situações de resolução de problemas e os invariantes operatórios foram utilizados.

Com relação ao estudo do tópico de Estatísticas, foram selecionados cinco trabalhos: D1, D3, D6, D2 e T1. D1 procurou relacionar os invariantes operatórios presentes nas covariações, mais especificamente os teoremasem-ação e os conceitos-em-ação em situações de resolução de problemas. D3 realizou um estudo nos livros didáticos relacionado ao conceito de média aritmética, em que as atividades foram classificadas e organizadas com enfoque em invariantes, significados, representações exploradas e tipo de contexto e as variáveis envolvidas. D6 procurou utilizar teoremas-em-ação que foram associados aos três níveis de letramento estatístico (cultural, funcional e científico) fazendo uma conexão com o contexto socioambiental. D2 tratou da significação com intervenções voltadas para a conceitualização. T1 procurou entender o processo de formação do raciocínio estatístico por meio da conceitualização, além dos invariantes operatórios (conceito-em-ação e teorema-em-ação) durante a resolução das situações-problemas.

\section{Considerações finais}

Todos os trabalhos selecionados apresentaram uma fundamentação voltada para a Teoria dos Campos Conceituais. Dentre as contribuições dessa teoria para o ensino de Estatística e Probabilidadeestá o seu potencial para o ensino e aprendizagem por meio dos invariantes descritos (teorema-as-ação e conceito-em-ação).

Verificou-se que todos os estudos selecionados tiveram uma forma específica de utilizar a Teoria dos Campos Conceituais em suas análises, cada um com sua particularidade, uns se envolveram mais com as invariantes operatórias, outros se preocuparam mais com as situações. O que se pode notar é que os conceitos estão presentes em situações distintas, os invariantes e esquemas implicam em ações dos sujeitos sobre essas situações e podem ser representadas por meio da linguagem ou símbolos.

No entanto, foram encontrados poucos trabalhos envolvendo os campos conceituais e o ensino de probabilidade e estatística. Isso leva a concluir que há necessidade de mais trabalhos voltados para os campos conceituais e os conceitos de probabilidade e estatística.

\section{Referências bibliográficas}

BUENO, A. J. A., ISHIKAWA, E. C. M., dos SANTOS JUNIOR, G., \& TENÓRIO, M. M. (2016). Mestrados acadêmicos e doutorados no Brasil (2004 a 2014) da área ensino: temas para o ensino de probabilidade e estatística. Revista ESPACIOS. Vol. 37 (21). DOI: 10.48082/espacios-

CABERLIM, C. C. L. (2015). Letramento probabilístico no ensino médio: um estudo de invariantes operatórios mobilizados por alunos. Dissertação de mestrado. São Paulo: Pontifícia Universidade Católica de São Paulo.

CARVALHO, J. I. F. D. (2011). Média aritmética nos livros didáticos dos anos finais do ensino fundamental (Master's thesis, Universidade Federal de Pernambuco).

CASTRO, Juscileide Braga de (2016). Construção do conceito de covariação por estudantes do ensino fundamental em ambientes de múltiplas representações com suporte das tecnologias digitais. $275 f$. 2016. Tese de Doutorado. Tese (Doutorado) -Universidade Federal do Ceará, Programa de Pós-graduação em Educação Brasileira, Fortaleza (CE). 
CHAGAS, R. M. das (2010). Estatística para alunos do 60 ano do ensino fundamental: um estudo dos conceitos mobilizados na resolução de problemas. 125f. Dissertação (Mestrado em Educação Matemática) Pontifícia Universidade Católica de São Paulo, São Paulo.

Cedran, D. P., \& Kiouranis, N. M. M. (2019). Teoria dos campos conceituais: visitando seus principais fundamentos e perspectivas para o ensino de ciências. ACTIO, 4 (1), 63-86.

Kitchenham, B. (2004). Procedures for performing systematic reviews. Keele, UK, Keele University, 33(2004), 126.

Leite, A. P. F. (2010). Estimativa de Medidas de Tendência Central: uma intervenção de ensino. Mestrado Profissional em Ensino de Matemática) Pontifícia Universidade Católica de São Paulo.

Meneghetti, R. C. G., de Fátima Batistela, R., \& Bicudo, M. A. V. (2011). A Pesquisa sobre o Ensino de Probabilidade e Estatística no Brasil: um exercício de metacompreensão. Boletim de Educação Matemática, 24(40), 811-833.

Moreira, M. A. (1999). Teorias de aprendizagem (Vol. 2). São Paulo: Editora pedagógica e universitária.

Moreira, M. A. (2002). A teoria dos campos conceituais de Vergnaud, o ensino de ciências e a pesquisa nesta área. Investigações em ensino de ciências. Porto Alegre. Vol. 7, n. 1 (jan./mar. 2002), p. 7-29.

Rother, E. T. (2007). Revisão sistemática X revisão narrativa. Acta paulista de enfermagem, 20(2), v-vi.

Sampaio, R. F., \& Mancini, M. C. (2007). Estudos de revisão sistemática: um guia para síntese criteriosa da evidência científica. Brazilian Journal of Physical Therapy, 11(1), 83-89.

Santana, M. R. M.(2011). O acaso, o provável, o determinístico: concepções e conhecimentos probabilísticos de professores do ensino fundamental. Dissertação de Mestrado. Universidade Federal de Pernambuco.

Sturion, L., Carvalho, A. A. A., REIS, M., \& ROCHA, Z. (2018). As dificuldades dos professores de estatística na utilização de tecnologias midiáticas. Revista de Ensino de Ciências e Matemática (REnCiMa), 9, 78-93.

Vergnaud, G. (1986). Psicologia do desenvolvimento cognitivo e didáctica das matemáticas. Um exemplo: as estruturas aditivas. Análise psicológica, 5, 75-90.

Vergnaud, G. (1990). La teoría de los campos conceptuales. Recherches en didactique de mathématiques, 10(2), 3.

Vergnaud, G.et al (1993). Teoria dos campos conceituais. Anais do 1o Seminário Internacional de Educação Matemática do Rio de Janeiro, p. 1-26.

Vergnaud, G. (2007). ¿ En qué sentido la teoría de los campos conceptuales puede ayudarnos para facilitar aprendizaje significativo?. Investigações em ensino de ciências, 12(2), 285-302.

Vergnaud, G. (2011). O longo e o curto prazo na aprendizagem da matemática. Educar em Revista, 15-27.

Vergnaud, G. (2012). Forme opératoire et forme prédicative de la connaissance. Investigações em Ensino de Ciências, 17(2), 287-304.

Vergnaud, G. (2013). Pourquoi la théorie des champs conceptuels?. Infancia y Aprendizaje, 36(2), 131-161.

Vergnaud, G. (2018). A simbolização e a conceitualização. In: Colóquio internacional sobre a teoria dos campos conceituais, Porto Alegre. Anais. Porto Alegre: GEEMPA.

Esta obra está bajo una Licencia Creative Commons Attribución-NoCommercial 4.0 International

(cc) $\overline{\text { BY-NO }}$ 